\title{
Expression and in vitro assessment of tumorigenicity for NOD1 and NOD2 receptors in breast cancer cell lines
}

\author{
Fernando J. Velloso ${ }^{1}$, Mari Cleide Sogayar ${ }^{1}$ and Ricardo G. Correa ${ }^{2^{*}}$ (D)
}

\begin{abstract}
Objective: Immune-related pathways have been frequently associated to tumorigenesis. NOD1 and NOD2 are innate immune receptors responsible for sensing a subset of bacterial-derived components, and to further translate these pathogenic signals through pro-inflammatory and survival pathways. NOD1 and NOD2 have been further associated with tumorigenesis, particularly in gastrointestinal cancers. NOD1 has also been suggested to be a tumor suppressor gene in a model of estrogen receptor-dependent breast cancer. Contrarily, NOD2 polymorphisms are associated with higher risk of breast cancer, with no tumor suppressor role being reported. To better delineate this issue, we investigated NOD1 and NOD2 expression in a panel of breast cancer cell lines, as well as their potential impact in breast tumorigenesis based on in vitro assays.

Results: The highly invasive Hs578T breast cell line presented the second highest NOD1 expression and the lowest NOD2 expression in our panel. Therefore, we investigated whether NOD1 and/or NOD2 might act as a tumor suppressor in this cell model. Our studies indicate that overexpression of either NOD1 or NOD2 reduces cell proliferation and increases clonogenic potential in vitro. Elucidation of NOD1 and NOD2 effects on tumor cell viability and proliferation may unveil potential targets for future therapeutic intervention.
\end{abstract}

Keywords: NOD1, NOD2, NLR, Hs578T, Breast cancer, Y-Tri-DAP, MDP

\section{Introduction}

Breast cancer is the malignancy with the highest incidence in women worldwide, accounting for $29 \%$ of all diagnosed cancers in females [1]. Despite clinical improvements in diagnosis and treatment, breast cancer remains the leading cause of cancer mortality among women, representing $14 \%$ of all deaths from cancer in women [2], mostly associated to metastatic tumors [3].

Breast cancer is classified according to immunohistological detection of protein markers, including receptors for estrogen (ER), progesterone (PR), androgen (AR), and the amplified HER2 (Human Epidermal Growth Factor Receptor 2) receptor [4]. Approximately $15 \%$ of all breast tumors lack expression of ER, PR and amplification of

\footnotetext{
${ }^{*}$ Correspondence: rcorrea@sbpdiscovery.org

${ }^{2}$ Sanford Burnham Prebys Medical Discovery Institute, 10901 North

Torrey Pines Rd., La Jolla, CA 92037, USA

Full list of author information is available at the end of the article
}

HER2, being therefore classified as triple negative breast cancers (TNBC). The absence of well-defined molecular targets, such as ER $\alpha$ and PR, prevents the use of selective drug therapies, rendering TNBC the most lethal type of breast cancer $[5,6]$.

Inflammation is an important underlying factor for cancer development [7]. In a number of tissues, including breast, tumor onset and progression have been associated to immune-related molecules, such as interleukins, caspases and a set of cytosolic receptors called NLRs (NACHT and Leucine Rich Repeat domain containing proteins). NLRs are pattern recognition receptors (PRRs) which recognize both pathogen-associated molecular patterns (PAMPs) and danger associated molecular patterns (DAMPs), thus acting as innate immunity "sensors" towards pathogen-derived components and cellular damage/stress. NOD1 and NOD2 (nucleotide-binding oligomerization domain-containing protein 1 and 2) are 
two major NLRs that directly modulate pro-inflammatory pathways, including NF-kB and MAPK [8]. NOD1 and NOD2 display variable tandem C-terminal leucinerich repeat domains (LRRs), which are responsible for ligand recognition and allow these receptors to detect the bacterial peptidoglycan iE-DAP (gamma-D-glutamylmeso-diaminopimelic acid) and MDP (muramyl dipeptide), respectively [8]. Ligand-bound NOD1 and NOD2 recruit RIP2, which activates the IKK complex towards NF- $\mathrm{KB}$ and stress kinase cascades through MAPKs [9].

Persistent activation and deficiency of NOD1 and NOD2 receptors have been associated to gastrointestinal cancers [10]. In other tissues, including breast, NOD1 and NOD2 knockdown models display increased predisposition for tumorigenesis [11]. Additionally, NOD1 and NOD2 polymorphisms have been associated to increased risk for several cancer types, including breast $[12,13]$. In the estrogen-dependent MCF7 breast cancer cell line, NOD1 activation was shown to promote RIP2 and caspase 8-mediated apoptosis and to reduce estrogen-induced proliferative responses in vitro [14]. Likewise, the absence of NOD1 leads to increased sensitivity to estrogen-induced cell proliferation and a failure to undergo NOD1-dependent apoptosis. Upon injection into a severe combined immune deficiency (SCID) mouse xenograft model, MCF7 cells lacking NOD1 displayed increased estrogen-dependent tumor growth [15]. Moreover, NOD1 overexpression halted estrogen-dependent tumor proliferation. Therefore, NOD1 has been proposed to act as a tumor suppressor gene in ER-positive cells. Contrarily, NOD2 activation does not induce apoptosis in this cell line $[14,15]$.

In order to determine whether NOD1 and/or NOD2 play significant roles in the onset and progression of breast cancer, here we evaluated the expression of NOD1 and NOD2 in a panel of progressively invasive breast cancer-derived cell lineages. In addition, we analyzed the impact of NOD1 and NOD2 overexpression in breast cancer, based on cell proliferation and clonogenic assays.

\section{Main text \\ Methods \\ NOD1 and NOD2 expression profiling in breast cancer derived cell lines}

Expression profiling was obtained for a panel of breast cancer derived cell lines, including non-tumorigenic MCF10A (ATCC ${ }^{\circledR}:$ CRL-10317 $^{\mathrm{TM}}$; $\quad$ ER-/PR-/AR-/ HER2-) and MCF12A (ATCC ${ }^{\circledR}: \mathrm{CRL}^{-10782^{\mathrm{TM}}}$; ER-/ PR-/AR+/HER2-), estrogen-positive MCF-7 (ATCC $\left.{ }^{(8)} \mathrm{HTB}-22^{\mathrm{TM}} ; \mathrm{ER}+/ \mathrm{PR}+/ \mathrm{AR}+/ \mathrm{HER} 2-\right)$ and $\mathrm{ZR}-75-1$ (ATCC $^{\circledR}$ CRL-1500 $^{\mathrm{TM}} ; \mathrm{ER}+/ \mathrm{PR}+/ \mathrm{AR}+/ \mathrm{HER} 2+$ ), and estrogen-negative SK-BR-3 (ATCC ${ }^{\circledR}$ HTB- $30^{\text {TM }}$; ER-/ PR-/AR+/HER2+), MDA-MB-231 $\left(\right.$ ATCC $^{\circledR}$ HTB- $26 ~^{\text {TM }}$;
ER-/PR-/AR+/HER2-) and Hs578T (ATCC ${ }^{\circledR}$ HTB$\left.126^{\mathrm{TM}} ; \mathrm{ER}-/ \mathrm{PR}-/ \mathrm{AR}+/ \mathrm{HER} 2-\right)$. Cells lines were obtained from ATCC (American Type Culture Collection) and analyzed at low passages (3-6) to avoid genetic drift aberrations. Replicated experiments were carried out with cells at increasing sequential passages.

Total RNA was isolated using Trizol reagent (Thermo), followed by DNAse I treatment (Thermo) for $20 \mathrm{~min}$ at $37^{\circ} \mathrm{C}$. Reverse transcription was performed using Superscript III polymerase (Thermo), according to manufacturer's protocols. RT-qPCR was carried out using FAST SYBR Green Master Mix (Thermo) in a ViiA 7 Real-Time PCR System (Thermo). Transcript amount quantification was calculated using the Comparative CT Method $(\Delta \Delta \mathrm{Ct}$; [16]), based on three technical replicates, with the QuantStudio $^{\mathrm{TM}}$ Software V1.3 (Thermo). Graph design and statistical analyses were performed in Graphpad Prism V6 (Graphpad Software). Primers for the following human genes were synthesized (IDT): NOD1 (forward: 5'-CTGCTCACTCAGAGCAAAGTCGT-3'; reverse: 5'-GTCCATGTAGATCTCCTCCAGCA-3'), NOD2 (forward: 5'-AAATCAGGTTGCCGATCTTCA-3'; reverse: 5'-CAGCCAATCCATTCGCTTTC-3'), RPL13A (forward: $\quad 5^{\prime}$-CCTGGAGGAGAAGAGGAAAGAGA-3'; reverse: 5'-TTGAGGACCTCTGTGTATTTGTCAA-3'), $H M B S$ (forward: 5'-TGGACCTGGTTGTTCACTCCTT3'; reverse: 5'-CAACAGCATCATGAGGGTTTTC-3').

\section{Overexpression of NOD1 and NOD2 in Hs578T breast cancer cells}

NOD1 and NOD2 cDNAs were previously subcloned into a lentiviral 6xHis-FLAG-containing vector, co-expressing EGFP under an IRES sequence [17]. Lentivirus production followed as previously described [18]. Hs578T cells were transduced by spinfection $(\mathrm{MOI}>5)$. Transduced GFP-positive cells were sorted using a FACS Aria II flow cytometer (BD Biosciences).

\section{Western blotting}

Ectopic proteins were detected by immunoblotting using mouse monoclonal anti-FLAG antibody (ab18230, Abcam). Reversible Ponceau staining was used to control the equal loading of protein lysates.

\section{Growth curves}

$5 \times 10^{3}$ cells from each population were cultured in $3.8 \mathrm{~cm}^{2}$ wells (12-well plate) for 6 days. Cells were harvested every $24 \mathrm{~h}$ and the total cell number was obtained using the Accuri C6 Plus flow cytometry system (BD Biosciences). Statistical analysis was carried out using Graphpad Prism V6 (Graphpad Software), with two-way repeated measures ANOVA test $(n=3 ; 0.05$ alpha), querying the cell populations as the source of variation. 
Population doubling time (PDT), was calculated from the equation $\Delta t \times[\ln 2 /(\ln N t-\ln N 0)]$, where $\Delta t$ is the duration of cell proliferation (exponential phase) in hours, and $\mathrm{NO}$ and $\mathrm{Nt}$ are the respective numbers of cells at the beginning and end of this period $[19,20]$.

\section{Colony formation assay in solid substrate}

$2 \times 10^{2}$ cells from each population were cultured in $9.5 \mathrm{~cm}^{2}$ wells (6-well plate) for 12 days. Colonies were counted after fixation (4\% formaldehyde; Sigma Aldrich) and staining (0.05\% crystal violet). Statistical analysis was performed using two-tailed, unpaired, student's t-test $(\mathrm{n}=3 ; 0.05$ alpha) (Graphpad Prism V6).

\section{Colony formation assay in soft-agar substrate}

$1 \times 10^{4}$ cells from each population were seeded in $1.9 \mathrm{~cm}^{2}$ wells (24-well plate) previously covered with $0.5 \mathrm{~mL}$ DMEM growth medium containing $0.6 \%$ agar. After seeding, a layer of $0.5 \mathrm{~mL} 0.3 \%$ agar DMEM was added and allowed to gellify before addition of $0.5 \mathrm{~mL}$ DMEM per well. Cultures were maintained for 14 days. Colonies were fixed in $4 \%$ formaldehyde and counted. Statistical analysis was performed using two-tailed, unpaired, student's t-test ( $\mathrm{n}=4 ; 0.05$ alpha) (Graphpad Prism V6).

\section{Results}

NOD1 and NOD2 are differentially expressed in breast cancer cell lines

Figure 1 shows the expression profiles of NOD1 and NOD2 genes in a panel of breast cancer-derived cell lines, including estrogen-positive (MCF-7 and ZR-75-1) and estrogen-negative (MCF10A, MCF12A, SK-BR-3, MDAMB-231 and Hs578T) cell lines. We found that NOD1 and NOD2 expression varies among these cell lines, with no clear pattern discriminating estrogen receptor-positive or negative groups. Interestingly, the Hs578T cell line presented the highest expression of NOD1 and the lowest expression of NOD2 in our panel. Due to its specific characteristics, namely, its tumorigenic potential and TNBC origin [21], we decided to overexpress NOD1 or NOD2 in Hs578T cells for further functional studies.

\section{Overexpression status of NOD1/2 in transduced Hs578T cells}

Hs578T/NOD1 and Hs578T/NOD2 populations were generated, overexpressing high amounts of ectopic NOD1 and NOD2 at both mRNA and protein levels (Fig. 2a, b). A control population, expressing only GFP, displayed NOD1 and NOD2 expression levels similar to those of the wild-type Hs578T cell line (Fig. 2a). Since Hs578T/NOD cells co-express GFP [17, 18], we used flow cytometry to ensure over $97 \%$ enrichment in GFPpositive cell content (Fig. 2c).
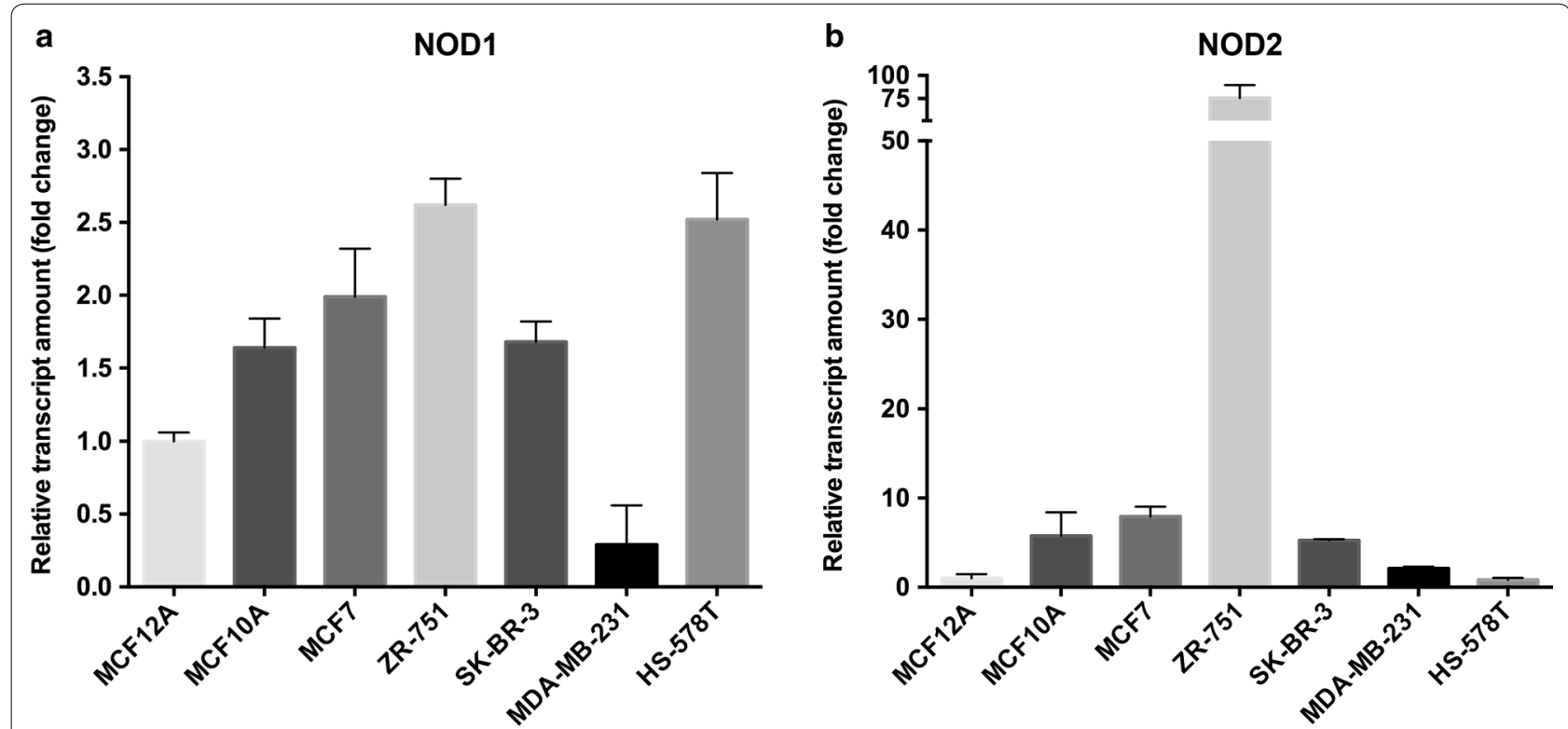

Fig. 1 NOD1 and NOD2 expression in breast cancer cells. Relative mRNA quantitation was performed by RT-qPCR, using a panel of breast cancer cell lineages. Values are presented as fold change relative to expression in the non-tumorigenic MCF12A cell line, after normalization using RPL13A and HMBS as endogenous controls (mean + standard deviation, $\mathrm{n}=3$ ) 


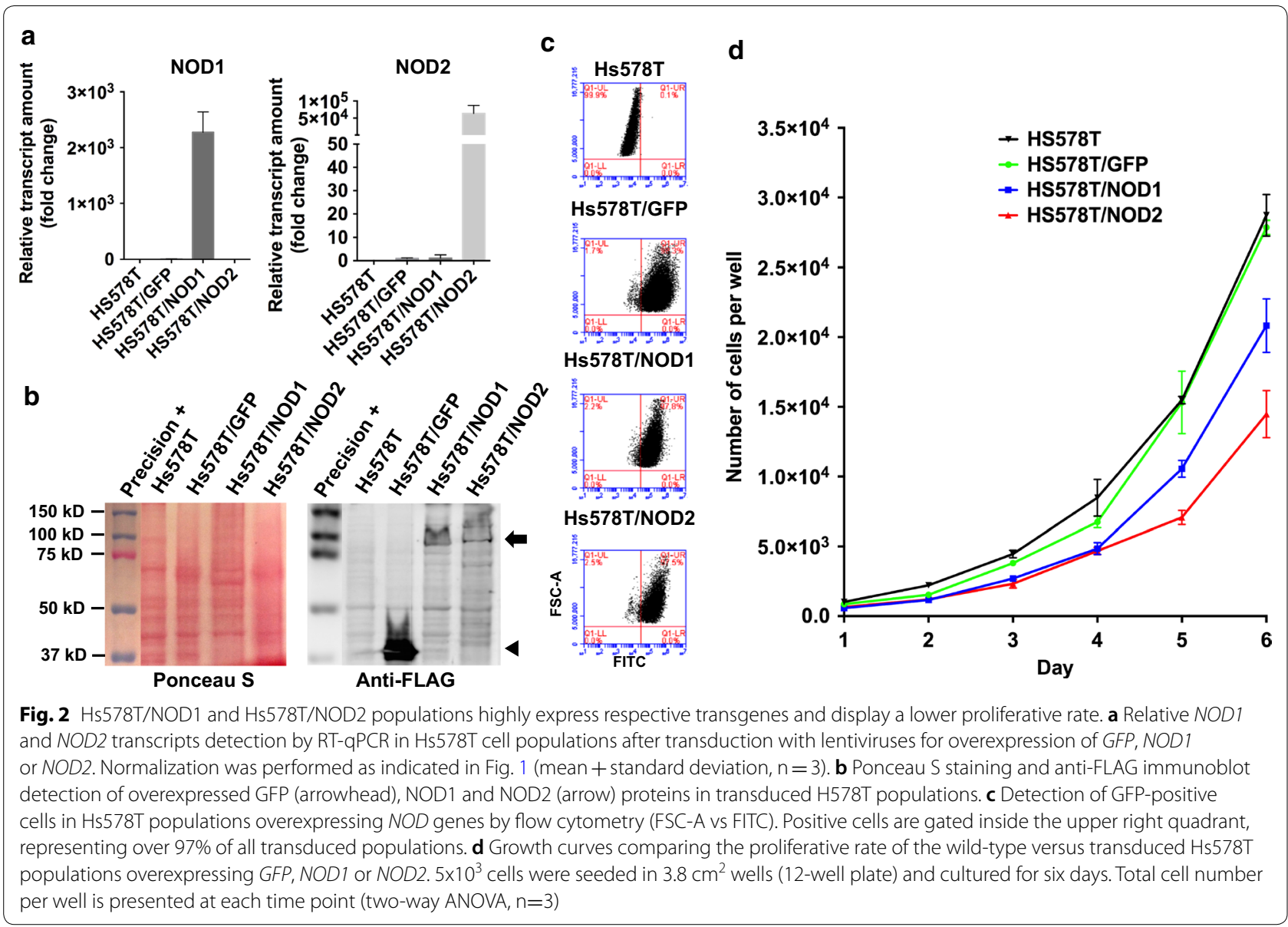

\section{Hs578T/NOD1 and Hs578T/NOD2 populations display a lower proliferation rate}

In vitro assays were carried out, with cell populations overexpressing $N O D 1 / 2$, to assess their proliferative potential and viability. Hs578T/NOD1 and Hs578T/ NOD2 displayed decreased proliferative rates when compared to wild-type (Hs578T) and GFP-only control cells (two-way ANOVA, $\mathrm{P} \leq 0.005, \mathrm{n}=3$ ). Control populations (wild-type and GFP-transduced cells) displayed statistically identical proliferative rates, with doubling times of 24.9 and $23.9 \mathrm{~h}$, respectively. Intriguingly, the Hs578T/ NOD2 population displayed the lowest growth rate, even when compared to Hs578T/NOD1 cells (33.4 vs. 28.9 h, respectively) (Fig. $2 \mathrm{~d}$ ).

\section{Hs578T/NOD1 and Hs578T/NOD2 cell populations display higher cellular viability}

We employed in vitro colony formation assays to infer tumor growth and viability of the NOD1/2-overexpressing populations. Upon seeding on solid substrate, the control populations presented statistically similar number of colonies per well. However, Hs578T/NOD1 cells showed an increased number of colonies formed per well (unpaired student's t-test; $\mathrm{P}<0.05 ; \mathrm{n}=3$ ) when compared to the controls. This effect was further enhanced by treatment with $5 \mu \mathrm{g} / \mathrm{mL} \gamma$-tri-DAP, a NOD1-specific agonist (unpaired student's t-test; $\mathrm{P} \leq 0.01 ; \mathrm{n}=3$ ). Hs578T/ NOD2 displayed a non-statistical tendency for increased number of colonies in the absence of any treatment, and a statistically significant increase in colony number upon treatment with $5 \mu \mathrm{g} / \mathrm{mL}$ MDP, a NOD2-specific agonist (unpaired student's t-test; $\mathrm{P} \leq 0.01 ; \mathrm{n}=3$ ) (Fig. 3a, b).

\section{Hs578T/NOD1 and Hs578T/NOD2 display higher anchorage-independent growth}

The ability to form colonies in soft agar, a close in vitro approximation of the in vivo tumorigenic potential, was also investigated. As shown in Fig. 3c, both Hs578T/ NOD1 and Hs578T/NOD2 cells displayed an increased number of colonies in semi-solid substrate (unpaired student's t-test; $\mathrm{P}<0.01 ; \mathrm{n}=4$; unpaired student's t-test; $\mathrm{P} \leq 0.001 ; \mathrm{n}=4)$. Again, this effect was further enhanced by treatment with $5 \mu \mathrm{g} / \mathrm{mL} \gamma$-tri-DAP (unpaired student's 
a

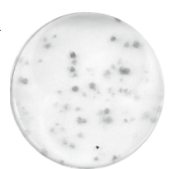

HS578T

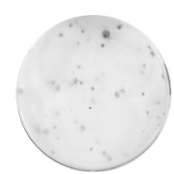

HS57T/

GFP

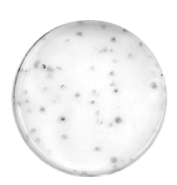

HS578T/

GFP

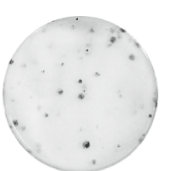

HS578T/

GFP

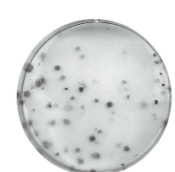

HS578T/ NOD1

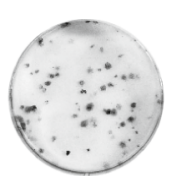

HS578T/

NOD1

Tri-DAP

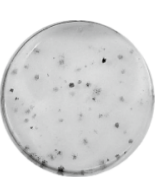

HS578T/

NOD2

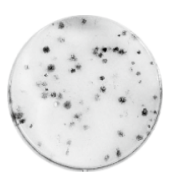

HS578T/

NOD2
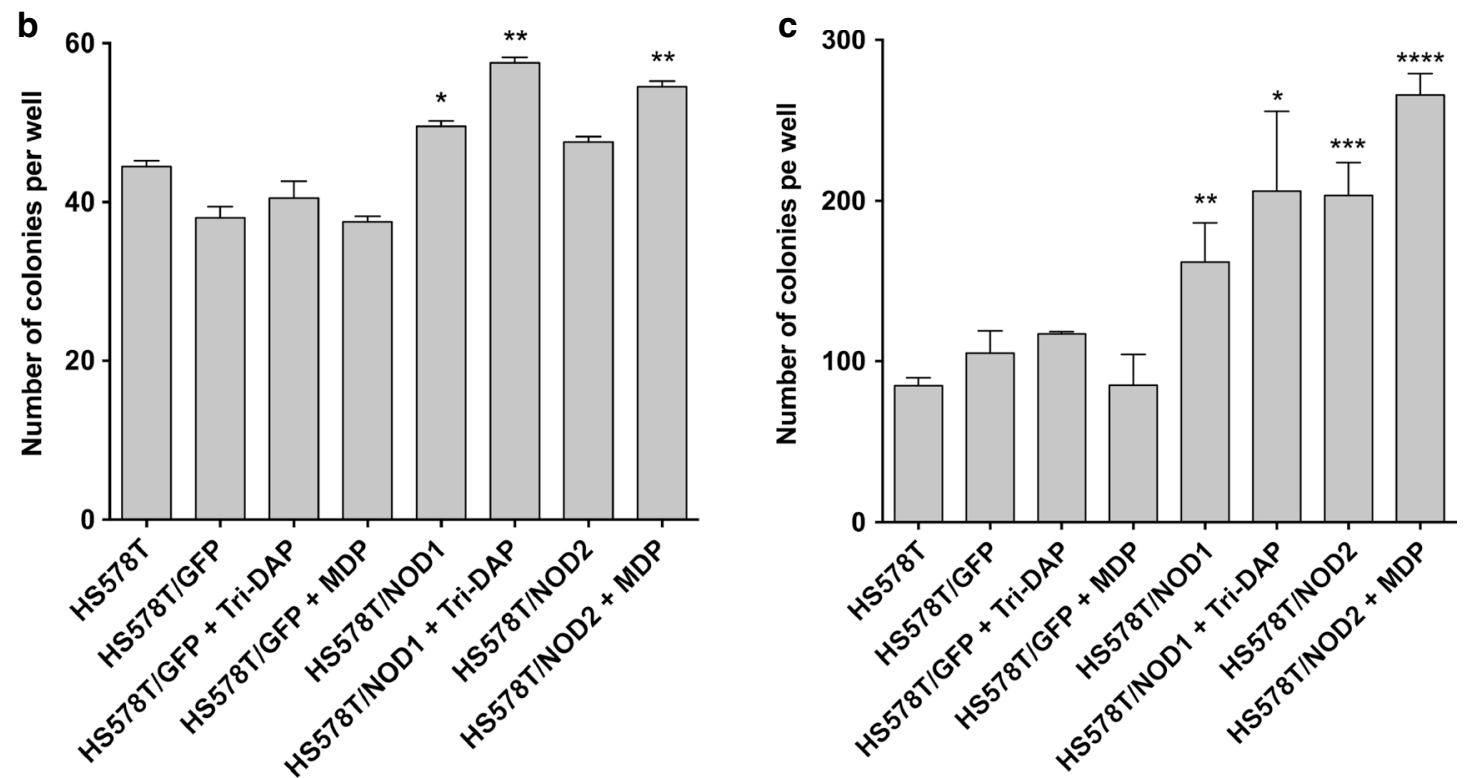

Fig. $3 \mathrm{H} 5578 \mathrm{~T} / \mathrm{NOD} 1$ and Hs578T/NOD2 cell populations display higher viability in solid substrate and in soft agarose, and this effect is enhanced by NOD1/2 agonists. Colony formation assays, comparing the total number of colonies per well, from wild-type or transduced Hs578T populations overexpressing GFP, NOD1 or NOD2. a Images of colonies formed by the different Hs578T populations in solid substrate upon staining with crystal violet. b Total number of colonies formed per well in both $\mathbf{b}$ solid and $\mathbf{c}$ soft agarose substrates, by transduced Hs578T populations in comparison to the wild-type. In both assays, Hs578T/NOD1 and Hs578T/NOD2 populations were treated with $5 \mu \mathrm{g} / \mathrm{mL}$-tri-DAP and MDP (Invivogen), respectively (unpaired student's t-test; ${ }^{*} P \leq 0.05 ;{ }^{* *} P \leq 0.01 ;{ }^{* * *} P \leq 0.001 ;{ }^{* * *} P \leq 0.0001$. $\mathbf{a} n=3 ; \boldsymbol{b} n=4$ )

t-test; $\mathrm{P} \leq 0.05 ; \mathrm{n}=4$ ) or $5 \mu \mathrm{g} / \mathrm{mL}$ MDP (unpaired student's t-test; $\mathrm{P} \leq 0.0001 ; \mathrm{n}=4$ ) (Fig. 3c).

\section{Discussion}

Here, we show that $N O D 1$ and NOD2 display variable expression levels in a panel of estrogen receptor-positive and estrogen receptor-negative breast cancer cell lines. NOD1 was previously described as a possible tumor suppressor gene in an estrogen receptor-positive cellular model, acting through the blockage of ER $\alpha$ [15]. We elected the triple-negative Hs578T cell line to investigate whether the same effect would be observed in an estrogen receptor-negative cell line, by generating transduced cells overexpressing NOD1 or NOD2 receptors. In the aforementioned report on the estrogen receptor-positive model, NOD1 overexpression had no effect on cell proliferation, whereas silencing of this receptor actually increased the estrogen-dependent cell proliferation.
In our model, the NOD1 overexpressing cells displayed a decreased proliferative rate in vitro. Remarkably, NOD2 overexpression caused an even more pronounced decrease in cell proliferation. Therefore, our data suggest that both NOD1 and NOD2 signals may regulate cell proliferation in this TNBC model, through a presumptive ER-independent pathway.

Our in vitro colony formation assays indicated an increased viability and cell growth rate in NOD1- and NOD2-overexpressing Hs578T populations. An even more pronounced effect was found for NOD2 towards cell proliferation and colony formation. The impact of NOD1/2 overexpression in colony formation was also increased by specific agonists, further indicating that activation of these receptors is directly linked to the effects observed. The apparent contradiction between proliferation and colony formation in our model may be explained by the variety of signals triggered by NOD receptors in downstream pathways. The effects 
observed in cell proliferation may be a direct result of signals towards MAPK pathway, thus modulating cell cycle checkpoints. On the other hand, colony formation may be affected by signaling pathways related to NF- $\mathrm{kB}$, increasing cellular viability through apoptotic escape or promoting independence from contact and anchorage signals such as ECAD (E-cadherin) [22], ICAM1 (Intercellular adhesion molecule 1) [23] and VCAM1 (Vascular cell adhesion Molecule 1) [24].

Given the incidence and high mortality rate of TNBC, decoding sub-pathways through which NOD receptors modulate cell proliferation may offer potential new targets for future therapeutic interventions.

\section{Limitations}

A more conclusive assessment of NOD1/2 levels could benefit from western blot detection. However, due to their typically limited protein levels in a vast number of cell models, endogenous NOD1 and NOD2 amounts are usually evaluated by RT-qPCR $[15,17,25,26]$. As an example, immunoblot detection of NOD1 in HCT-116 cells, a bonafide cell model for NOD1/2 signaling, can only be achieved after immunoprecipitation and enrichment with a second NOD1 specific antibody [17].

Additionally, generating Hs578T populations with null expression of $N O D 1$ and/or NOD2 would provide a valuable functional corroboration model to complement our overexpression results. Also, determining the sensitivity to apoptotic induction in our overexpressing populations could allow a better understanding of the pathways participating in the cellular effects observed.

\begin{abstract}
Abbreviations
AR: Androgen receptor; DAMP: Danger-associated molecular patterns; ECAD: E-cadherin; ER: Estrogen receptor; ERa: Estrogen receptor alpha; HER2: Human epidermal growth factor receptor 2; iE-DAP: Gamma-D-glutamyl-mesodiaminopimelic acid; IKK: Inhibitor of KB (IKB) kinase; LRR: Leucine-rich repeat domain; MAPK: Mitogen-activated protein kinase; MDP: Muramyl dipeptide; NLR: NACHT and Leucine-Rich Repeat domain containing protein; NOD1: Nucleotide-binding Oligomerization Domain-containing protein 1; NOD2: Nucleotide-binding Oligomerization Domain-containing protein 2; PAMP: Pathogen-associated molecular pattern; PR: Progesterone receptor; PRR: Pattern recognition receptor; SCID: Severe combined immune deficiency; TNBC: Triple negative breast cancer; $y$-tri-DAP: L-Ala-y-D-Glu-mDAP; VCAM1:Vascular cell adhesion molecule 1.
\end{abstract}

\section{Authors' contributions}

FJV performed most of the wet-lab and statistical analyses, under RGC coordination. FJV and RGC wrote the manuscript. MCS and RGC outlined the original research proposal, discussed the results and revised the manuscript. All authors participated in manuscript preparation. All authors read and approved the final manuscript.

\section{Author details}

${ }^{1}$ Cell and Molecular Therapy Center (NUCEL-NETCEM), Internal Medicine Department, School of Medicine, University of São Paulo (USP), São Paulo, SP 05360-130, Brazil. ${ }^{2}$ Sanford Burnham Prebys Medical Discovery Institute, 10901 North Torrey Pines Rd., La Jolla, CA 92037, USA.

\section{Acknowledgements}

The authors thank Dr. Carlos D. Pereira (Butantan Institute, Sao Paulo, Brazil) for sharing cell lineages used in this study.

\section{Competing interests}

The authors declare that they have no competing interests.

\section{Availability of data and materials}

The datasets generated and/or analyzed during the current study are available from the corresponding author on reasonable request.

\section{Consent for publication}

Not applicable.

Ethics approval and consent to participate

Not applicable.

\section{Funding}

The present work was fully supported by the "Science without Borders" Program from CAPES (Federal Agency for Superior Education and Training, Brazil). F.J.V was also supported by grants from CAPES. M.C.S. was additionally supported by grants from FAPESP (São Paulo State Foundation for Research), CNPq (National Research Council), BNDES (Brazilian National Bank for Economic and Social Development), FINEP (Funding Authority for Studies and Projects), MCTI (Science, Technology and Innovation Ministry) and MS-DECIT (Science and Technology Department of the Health Ministry). R.G.C. was supported by a Special Visiting Researcher (PVE) grant from the "Science without Borders" Program (CAPES).

\section{Publisher's Note}

Springer Nature remains neutral with regard to jurisdictional claims in published maps and institutional affiliations.

Received: 20 September 2017 Accepted: 28 March 2018

Published online: 03 April 2018

\section{References}

1. Siegel R, Miller K, Jemal A. Cancer statistics, 2015. CA Cancer J Clin. 2015;65:29. https://doi.org/10.3322/caac.21254.

2. IARC. World cancer report 2014. World Health Organization; 2014. ISBN: 978-92-832-0443-5. http://publications.iarc.fr/Non-Series-Publications/ World-Cancer-Reports/World-Cancer-Report-2014. Accessed 13 Aug 2017.

3. Melzer C, von der Ohe J, Hass R. Breast carcinoma: from initial tumor cell detachment to settlement at secondary sites. Biomed Res Int. 2017;2017:1-11. https://doi.org/10.1155/2017/8534371.

4. Janczur Velloso F, Filipini Rodrigues Bianco A, Farias J, Torres N, Ferruzo $P$, Anschau $V$, et al. The crossroads of breast cancer progression: insights into the modulation of major signaling pathways. Onco Targets Ther. 2017;10:5491-524. https://doi.org/10.2147/OTT.S142154.

5. Abramson VG, Lehmann BD, Ballinger TJ, Pietenpol JA. Subtyping of triple-negative breast cancer: implications for therapy. Cancer. 2015;121:8-16. https://doi.org/10.1002/cncr.28914.

6. Dai X, Li T, Bai Z, Yang Y, Liu X, Zhan J, et al. Breast cancer intrinsic subtype classification, clinical use and future trends. Am J Cancer Res. 2015;5:2929-43.

7. Afonina IS, Zhong Z, Karin M, Beyaert R. Limiting inflammation-the negative regulation of NF-KB and the NLRP3 inflammasome. Nat Immunol. 2017;18:861-9. https://doi.org/10.1038/ni.3772.

8. Philpott DJ, Sorbara MT, Robertson SJ, Croitoru K, Girardin SE. NOD proteins: regulators of inflammation in health and disease. Nat Rev Immunol. 2014;14:9-23. https://doi.org/10.1038/nri3565.

9. Kanneganti T-D, Lamkanfi M, Núñez G. Intracellular NOD-like receptors in host defense and disease. Immunity. 2007;27:549-59. https://doi. org/10.1016/j.immuni.2007.10.002.

10. Werts C, Rubino S, Ling A, Girardin SE, Philpott DJ. Nod-like receptors in intestinal homeostasis, inflammation, and cancer. J Leukoc Biol. 2011;90:471-82. https://doi.org/10.1189/jlb.0411183. 
11. Moreno L, Gatheral T. Therapeutic targeting of NOD1 receptors. Br J Pharmacol. 2013;170:475-85. https://doi.org/10.1111/bph.12300.

12. Liu J, He C, Xu Q, Xing C, Yuan Y. NOD2 polymorphisms associated with cancer risk: a meta-analysis. PLoS ONE. 2014;9:e89340. https://doi. org/10.1371/journal.pone.0089340.

13. Kutikhin AG. Role of NOD1/CARD4 and NOD2/CARD15 gene polymorphisms in cancer etiology. Hum Immunol. 2011;72:955-68. https://doi. org/10.1016/j.humimm.2011.06.003.

14. da Silva Correia J, Miranda Y, Leonard N, Hsu J, Ulevitch RJ. Regulation of Nod1-mediated signaling pathways. Cell Death Differ. 2007;14:830-9. https://doi.org/10.1038/sj.cdd.4402070.

15. da Silva Correia J, Miranda Y, Austin-Brown N, Hsu J, Mathison J, Xiang R, et al. Nod1-dependent control of tumor growth. Proc Natl Acad Sci USA 2006;103:1840-5. https://doi.org/10.1073/pnas.0509228103.

16. Livak KJ, Schmittgen TD. Analysis of relative gene expression data using real-time quantitative PCR and the 2(-Delta Delta C(T)) Method. Methods. 2001;25:402-8. https://doi.org/10.1006/meth.2001.1262.

17. Correa RG, Khan PM, Askari N, Zhai D, Gerlic M, Brown B, et al. Discovery and characterization of 2-aminobenzimidazole derivatives as selective NOD1 inhibitors. Chem Biol. 2011;18:825-32. https://doi.org/10.1016/j. chembiol.2011.06.009

18. Askari N, Correa RG, Zhai D, Reed JC. Expression, purification, and characterization of recombinant NOD1 (NLRC1): a NLR family member. J Biotechnol. 2012;157:75-81. https://doi.org/10.1016/j.jbiotec.2011.10.007.

19. Murhammer DW. Useful tips, widely used techniques, and quantifying cell metabolic behavior. 2016. p. 3-22. https://doi. org/10.1007/978-1-4939-3043-2 1.

20. Roth V. Doubling time computing. 2006. http://www.doubling-time.com/ compute.php. Accessed 28 June 2017.
21. Hackett AJ, Smith HS, Springer EL, Owens RB, Nelson-Rees WA, Riggs JL, et al. Two syngeneic cell lines from human breast tissue: the aneuploid mammary epithelial (Hs578T) and the diploid myoepithelial (Hs578Bst) cell lines. J Natl Cancer Inst. 1977;58:1795-806.

22. Natividad JMM, Petit V, Huang X, de Palma G, Jury J, Sanz Y, et al. Commensal and probiotic bacteria influence intestinal barrier function and susceptibility to colitis in Nod1 -/_; Nod2 -/_mice. Inflamm Bowel Dis. 2012;18:1434-46. https://doi.org/10.1002/ibd.22848.

23. Shin WG, Park BJ, Lee SJ, Kim JG. Infection of human intestinal epithelial cells by invasive bacteria activates NF-KB and increases ICAM-1 expression through NOD1. Korean J Intern Med. 2017. https://doi.org/10.3904/ kjim.2015.409.

24. Wan M, Liu J, Ouyang X. Nucleotide-binding oligomerization domain 1 regulates Porphyromonas gingivalis - induced Vascular Cell Adhesion Molecule 1 and intercellular adhesion molecule 1 expression in endothelial cells through NF-kB pathway. J Periodontal Res. 2015;50:189-96. https ://doi.org/10.1111/jre.12192.

25. Shigeoka AA, Kambo A, Mathison JC, King AJ, Hall WF, da Silva Correia J, et al. Nod 1 and nod 2 are expressed in human and murine renal tubular epithelial cells and participate in renal ischemia reperfusion injury. J Immunol. 2010;184:2297-304. https://doi.org/10.4049/jimmunol.09030 65.

26. Granland C, Strunk T, Hibbert J, Prosser A, Simmer K, Burgner D, et al. NOD1 and NOD2 expression and function in very preterm infant mononuclear cells. Acta Paediatr. 2014;103:e212-8. https://doi.org/10.1111/ apa.12559.

\section{Submit your next manuscript to BioMed Central and we will help you at every step:}

- We accept pre-submission inquiries

- Our selector tool helps you to find the most relevant journal

- We provide round the clock customer support

- Convenient online submission

- Thorough peer review

- Inclusion in PubMed and all major indexing services

- Maximum visibility for your research

Submit your manuscript at www.biomedcentral com/submit 